\title{
Research on the index correlation of soil in the Xu Wei Lianyungang port
}

\author{
Wenbin Liu \\ ${ }^{1}$ Tianjin University, civil engineering institute, 92 Weijin Rd, Nankai District, Tianjin, 300072, China \\ ${ }^{2}$ CCCC Tianjin Port Engineering Institute Co., Ltd., 1002 South Dagu Rd, Hexi District, Tianjin, \\ 300222, China
}

Keywords: soft clay, index correlation, lab test, formula.

\begin{abstract}
The physical mechanical indexes should be obtained before the strengthening treatment on the reclaimed soft clay. The correlation is existed among the physical mechanical indexes of clay. This paper reveals the index correlation of clay in the Xu Wei Lianyungang port based on amount of lab test results. The fitting formula for the correlation relationship between the natural water content, void ratio, liquid limit and the compression modulus, compression coefficient is proposed.
\end{abstract}

\section{Introduction}

Different from the nature sedimentary soil, the reclaimed soft clay is consisted by lots of high natural water content, high compressibility and low bearing capacity mud deposit and little humus soil. The strength of reclaimed clay is weak and should be treated before acting as the foundation of buildings. Before processing the strengthening treatment, the engineering properties should be test first. The physical indexes of reclaimed soft clay mainly refers to the natural water content, the wet density, the void ratio, the liquid limit, the plastic limit and so on. The engineering mechanical indexes main refers to the compression modulus and compression coefficient. The traditional method for obtaining these indexes is carried out large amounts of model tests. Studying the correlational relationship of t0068ese indexes based on large number of existing test data can reduce the workload and improve the work efficiency.

\section{Study of the correlational relationship between physical indexes and mechanical engineering indexes}

\subsection{The correlational relationship between natural water content and mechanical engineering indexes}

Figure 1 show the relationship between the natural water content $w$ and the compression modulus $E_{\mathrm{s}}$, compression coefficient $\alpha_{\mathrm{v}}$.

Figure 1 shows that the compression modulus decreases with the increasing natural water content, and the relationship between them presents as a power function. The compression coefficient increases with the rising natural water content, and the relationship between them presented as an exponential function. The fitting functions are obtained using the least square method and displayed below.

$$
\begin{aligned}
& E_{\mathrm{s}}=741.04 w^{-1.466}, \quad \mathrm{R}^{2}=0.8335 \\
& \alpha_{\mathrm{s}}=0.0821 \mathrm{e}^{0.0474 v}, \quad \mathrm{R}^{2}=0.8946
\end{aligned}
$$



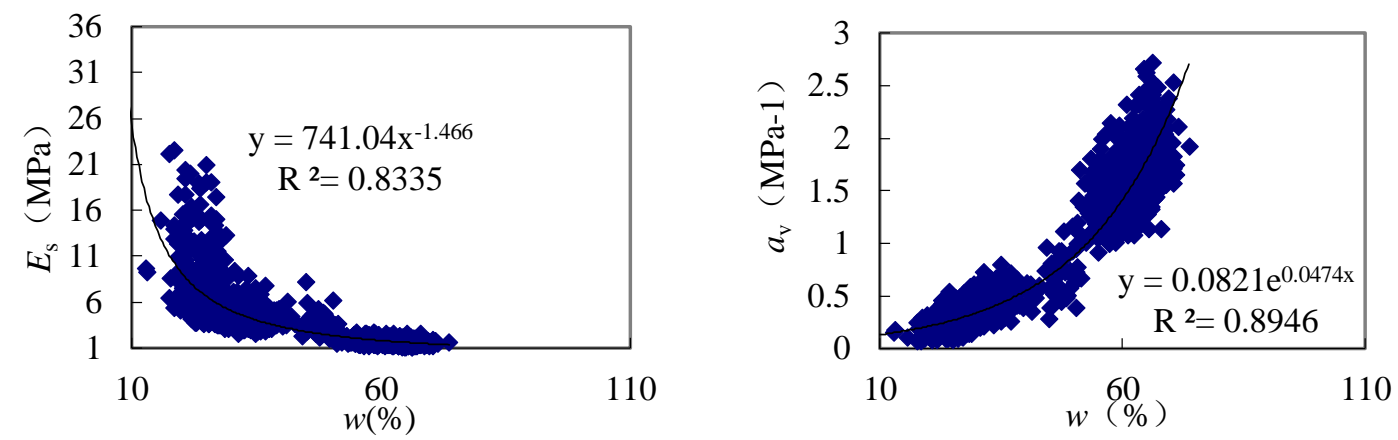

Figure 1 Relationship between $w$ and $E_{\mathrm{s}}, \alpha_{\mathrm{v}}$

\subsection{The correlational relationship between void ratio and mechanical engineering indexes}

Figure 2 show the relationship between the void ratio $e$ and the compression modulus $E_{\mathrm{s}}$, compression coefficient $\alpha_{\mathrm{v}}$.
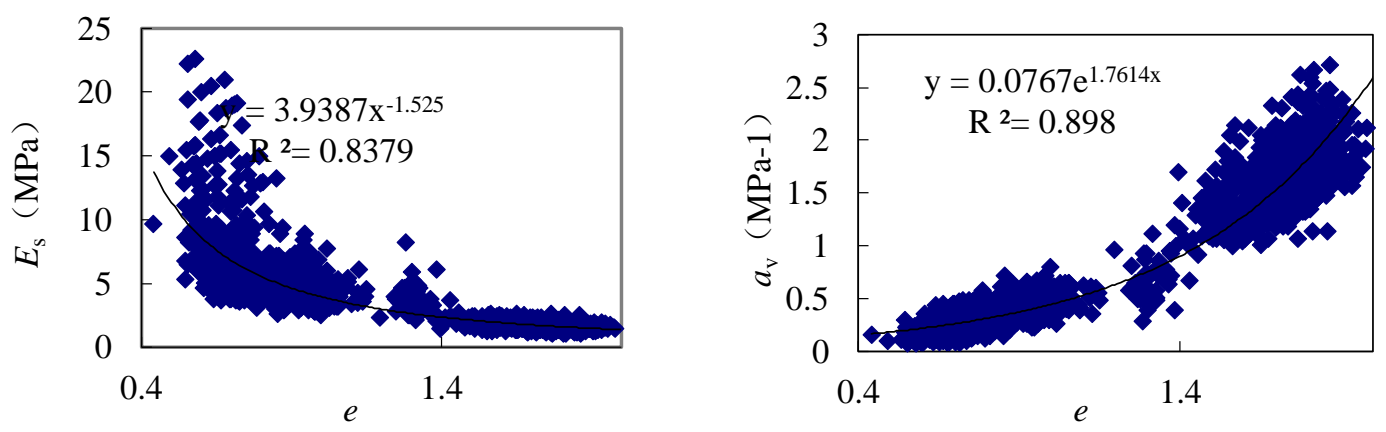

Figure 2 Relationship between $e$ and $E_{\mathrm{s}}, \alpha_{\mathrm{v}}$

Figure 2 shows that the compression modulus decreases with the increasing void ratio, while the compression coefficient increases with the rising void ratio. The fitting functions are also be concluded and shown as followed.

$$
\begin{aligned}
& E_{\mathrm{S}}=3.9387 e^{-1.525}, \quad \mathrm{R}^{2}=0.8379 \\
& \alpha_{\mathrm{s}}=0.0767 \mathrm{e}^{1.7614}, \quad \mathrm{R}^{2}=0.898
\end{aligned}
$$

2.3 The correlational relationship between plastic limit and mechanical engineering indexes

Figure 3 show the relationship between the plastic limit $\mathrm{WP}_{\mathrm{P}}$ and the compression modulus $E_{\mathrm{s}}$, compression coefficient $\alpha_{\mathrm{v}}$.
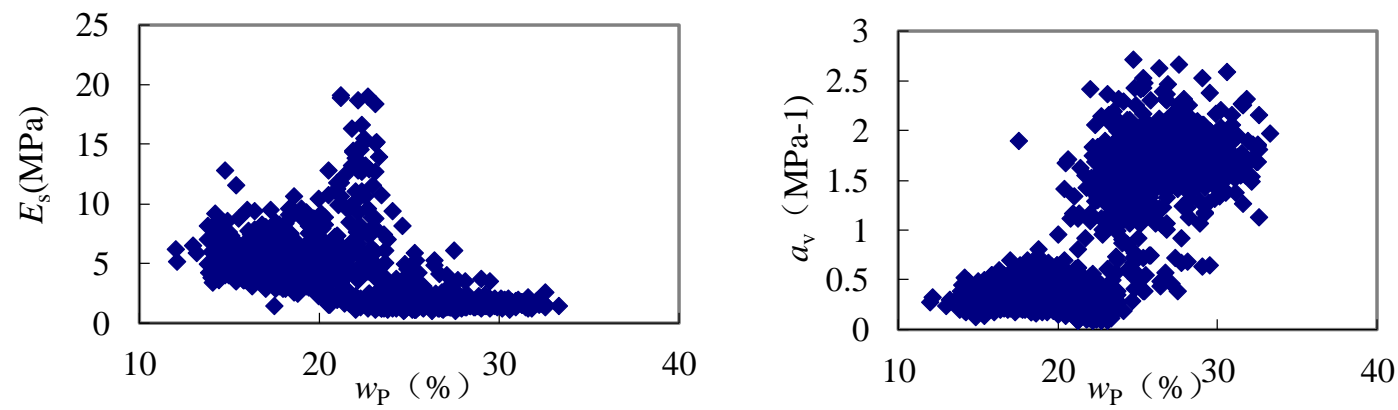

Figure 3 Relationship between $w_{\mathrm{P}}$ and $E_{\mathrm{s}}, \alpha_{\mathrm{v}}$

Figure 3 shows that the compression modulus decreases with the increasing plastic limit, while the compression coefficient increases with the rising plastic limit. The fitting functions are also be concluded and shown as followed.

\subsection{The correlational relationship between plastic index and mechanical engineering indexes}

Figure 4 show the relationship between the plastic index $I_{\mathrm{P}}$ and the compression modulus $E_{\mathrm{S}}$, compression coefficient $\alpha_{\mathrm{v}}$. 

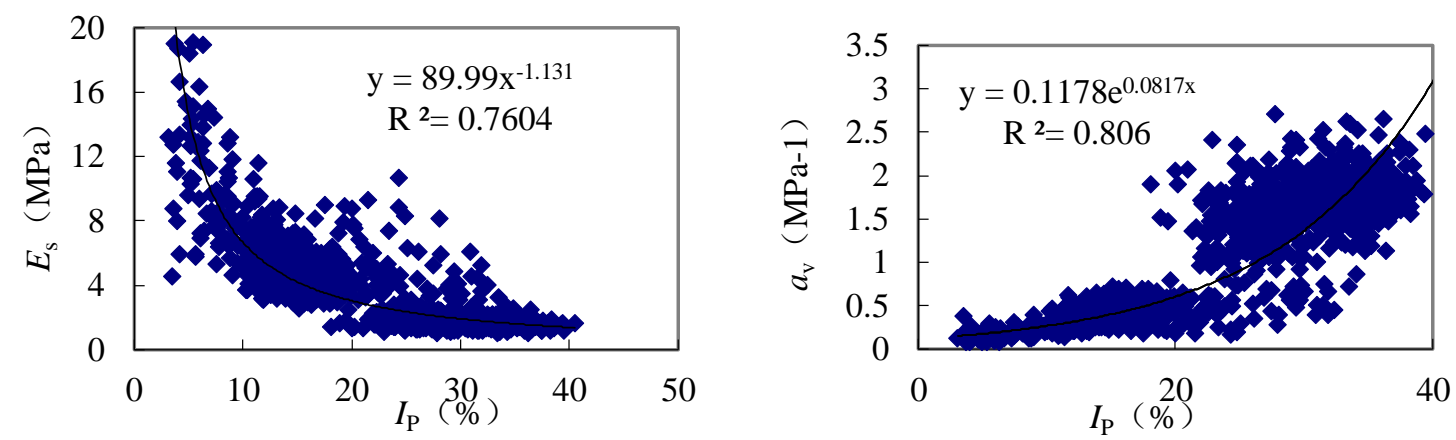

Figure 4 Relationship between $I_{\mathrm{P}}$ and $E_{\mathrm{s}}, \alpha_{\mathrm{v}}$

Figure 4 shows that the compression modulus decreases with the increasing plastic index, while the compression coefficient increases with the rising plastic index. The fitting functions are also be concluded and shown as followed.

$$
\begin{aligned}
& E_{\mathrm{S}}=89.99 I_{\mathrm{P}}^{-1.131}, \quad \mathrm{R}^{2}=0.7604 \\
& \alpha_{\mathrm{s}}=0.1178 \mathrm{e}^{0.081 \pi_{\mathrm{P}}}, \mathrm{R}^{2}=0.806
\end{aligned}
$$

\subsection{The correlational relationship between liquid limit and mechanical engineering indexes}

Figure 5 show the relationship between the liquid limit $w_{\mathrm{L}}$ and the compression modulus $E_{\mathrm{s}}$, compression coefficient $\alpha_{\mathrm{v}}$.
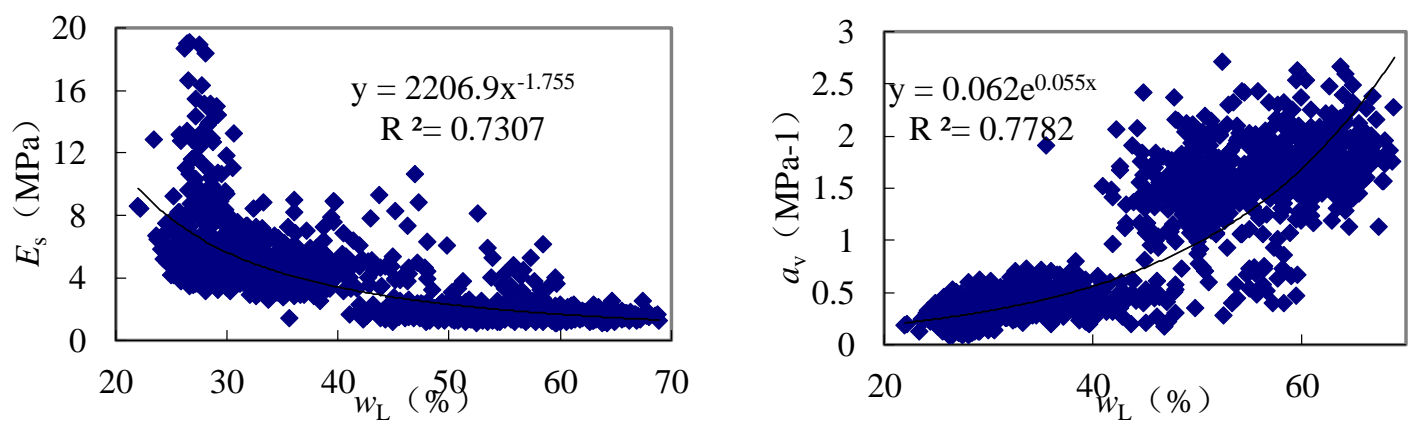

Figure 5 Relationship between $w_{\mathrm{L}}$ and $E_{\mathrm{s}}, \alpha_{\mathrm{v}}$

Figure 5 shows that the compression modulus decreases with the increasing liquid limit, while the compression coefficient increases with the rising liquid limit. The fitting functions are also be concluded and shown as followed.

$$
\begin{aligned}
& E_{\mathrm{S}}=2206.9 w_{\mathrm{L}}^{-1.755}, \quad \mathrm{R}^{2}=0.7309 \\
& \alpha_{\mathrm{s}}=0.062 \mathrm{e}^{0.055 v_{\mathrm{L}}}, \mathrm{R}^{2}=0.7782
\end{aligned}
$$

2.6 The correlational relationship between liquid index and mechanical engineering indexes

Figure 6 show the relationship between the liquid index $I_{\mathrm{L}}$ and the compression modulus $E_{\mathrm{S}}$, compression coefficient $\alpha_{\mathrm{v}}$.
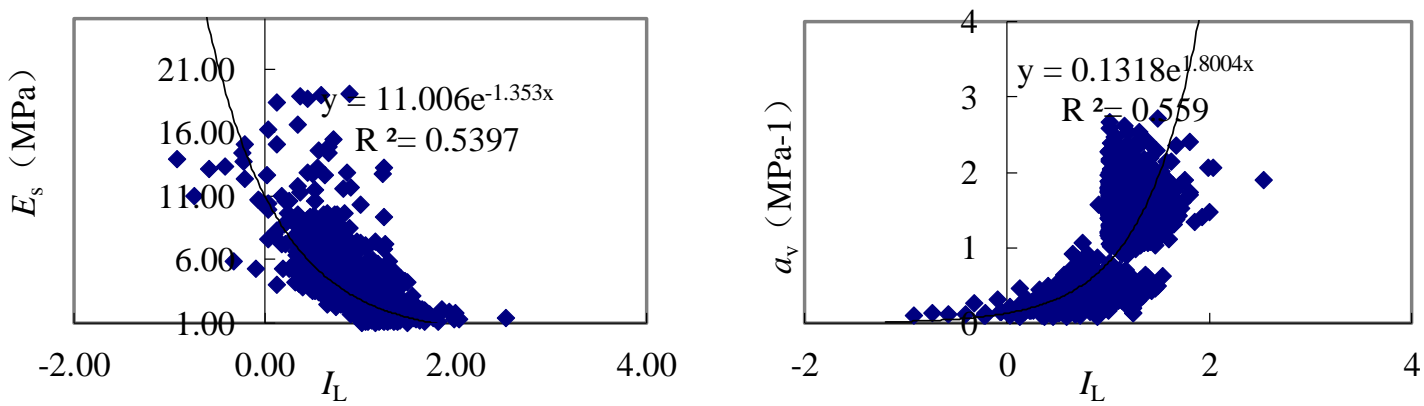

Figure 6 Relationship between $I_{\mathrm{L}}$ and $E_{\mathrm{s}}, \alpha_{\mathrm{v}}$

Figure 6 shows that the compression modulus decreases with the increasing liquid index, while the compression coefficient increases with the rising liquid index. The fitting functions are also be concluded and shown as followed.

$$
E_{\mathrm{S}}=11.006 \mathrm{e}^{-1.353_{\mathrm{L}}}, \quad \mathrm{R}^{2}=0.5397
$$




$$
\alpha_{\mathrm{S}}=0.1318 \mathrm{e}^{1.8004_{\mathrm{L}}}, \mathrm{R}^{2}=0.559
$$

\section{Conclusion}

Based masses of test data, the correlational relationship between the physical indexes and the mechanical engineering indexes are revealed by using mathematical statistics method. The studied show that:

(1) The relationship between compression modulus and the natural water content, void ratio, and compression coefficient presents well as a power function. The compression modulus decreases with the increasing natural water content and void ratio. The compression coefficient increases with the increasing natural water content and void ratio.

(2) The relationship between compression modulus, compression coefficient and plastic limit coincide with the fitting function not very well. The compression modulus decreases with the increasing plastic limit. The compression coefficient increases with the increasing plastic limit.

(3) The compression modulus decreases with the increasing liquid index and plastic index. The compression coefficient increases with the increasing liquid index and plastic index.

\section{Acknowledgements}

The authors are grateful for the support provided by Key Laboratory of Port Geotechnical Engineering of Tianjin and Key Laboratory of Port Geotechnical Engineering, Ministry of Communications, PRC.

\section{References}

[1]. Goovaerts, P., Geostatistical modeling of uncertainty in soil science [J], Geoderma, 2001, 103(1): 3-26.

[2]. Azm, S. A. H., Najat, T., Modeling uncertainty in stability analysis for design of embankment dams on difficult foundations [J], Engineering Geology, 2004, 71(3-4): 323-342. 